\title{
Fine SiC Inclusions and Grain Boundary Phases in Pressureless Sintered SiAlON
}

\author{
Weng-Cheng J. Wei ${ }^{a}$ \& John W. Halloran ${ }^{b}$ \\ "Institute of Materials Science and Engineering, National Taiwan University, Taipei, Taiwan 106 \\ ${ }^{b}$ Department of Materials Science and Engineering, University of Michigan, Ann Arbor, Michigan 48109, USA
}

(Received 6 December 1993; revised version received 27 April 1994; accepted 24 May 1994)

\section{Abstract}

The starting powder, synthesized by carbothermal reduction, was pressureless sintered at temperatures over $1670^{\circ} \mathrm{C}$ to produce a dense SiAlON ( $\mathrm{Si}_{6-z} \mathrm{Al}_{z}$. $\left.O_{z} N_{8--}\right)$ of $z=0.5$. The dense material was characterized by $X$-ray diffractometry (XRD), scanning electron microscopy (SEM) and analytical electron microscopy (AEM), showing a microstructure featuring $1 \mathrm{\mu m}$, equiaxed, $\beta^{\prime}$-grains bonded with a glassy phase. Fine SiC grains, $10-50 \mathrm{~nm}$ in size, were identified as inclusions in $\beta^{\prime}$-SiAlON grains or at the grain boundaries. $\alpha$-SiAlON grains or whiskers which alloyed with $Y$ and $C a$ were occasionally found in sizes less than $0.5 \mu \mathrm{m}$ located in glassy pockets at grain boundaries or on the oversintered surface. Several other phases, normally non-detectable from XRD spectra, were found at grain boundaries by TEM, including yttriumaluminum garnet $(Y A G),(\mathrm{Fe}, \mathrm{Zr}) \mathrm{Si}_{x}$, amorphous $\mathrm{SiO}_{\mathrm{r}}$ and elemental Si. The formation of $\mathrm{SiC}$ and other grain houndary phases is primarily due to the reducing atmosphere, chemistry of the matrix and neighboring glassy phase.

Das Ausgangspulver, das mittels carbothermischer Reduktion hergestellt wurde, wurde ohne Druck bei $1670^{\circ} \mathrm{C}$ gesintert, um dichtes SiAlON ( $\left.\mathrm{Si}_{6-z} \mathrm{Al}_{-} \mathrm{O}_{-} \mathrm{N}_{8-=}\right)$ mit $z=0.5$ herzustellen. Die Charakterisierung des Materials erfolgte durch Röntgenbeugung (XDR), Rasterelektronenmikroskopie (SEM) und analytische Elektronenmikroskopie (AEM). Das Mikrogefüge wies eine etwa $1 \mu \mathrm{m}$ Struktur auf, die aus $\beta$ '-Körnern und einer Glasphase bestand. Feine, etwa $10-50 \mathrm{~nm}$ große SiC-Körner konnten als Einschlüsse in $\beta^{\prime}$-SiAlON-Körnern oder an den Korngrenzen nachgewiesen werden. Mit $Y$ und $C a$ gemischte $\alpha$ SiAlON-Körner oder Whisker zeigten stellenweise eine Größe von weniger als $0.5 \mu \mathrm{m}$ und es befanden sich Glastaschen an den Korngrenzen oder auf der gesinterten Oberfläche. Mehrere andere Phasen, die normalerweise nicht in den XDR-Spektren zu erkennen sind, konnten mit Hilfe von TEM an den Korngrenzen nachgewiesen werden und enthielten Yttrium-Aluminium-Granat (YAG), (Fe, Zr)Si $i_{x}$ amorphes $\mathrm{SiO}_{x}$ und elementares Si. Die Bildung von $\mathrm{SiC}$ und anderen Korngrenzenphasen ist hauptsächlich auf die reduzierende Atmosphäre, die Matrixchemie und die benachbarte Glasphase zurückzuführen.

La poudre de départ, synthétisée par réduction carbothermique, a été densifiée par frittage naturel à des températures dépassant $1670^{\circ} \mathrm{C}$, résultant en un SiAlON dense $\left(\mathrm{Si}_{6-z} \mathrm{Al}_{z} \mathrm{O}_{z} \mathrm{~N}_{8-z}\right)$ d'une valeur de $z=0.5$. Le matériau dense a été caractérisé par diffraction des rayons $X(X R D)$, microscopie électronique à balayage (SEM) et par microscopie électronique analytique (AEM), montrant une microstructure proche de 1 um de grains equiaxes $\beta$ ' liés par une phase vitreuse. Des grains fins en $\mathrm{SiC}$, d'une taille comprise entre 10-50 $\mathrm{nm}$, ont été identifiés comme inclusions dans les grains de $\beta^{\prime}$-SiAlON, ou aux joints de grains. Des grains $\alpha$-SiAlON ou des trichites en alliage avec $Y$ et $\mathrm{Ca}$ ont été trouvés occasionnellement avec des tailles inférieures au $0.5 \mathrm{\mu m}$ dans les poches vitreuses ou sur la surface surfrittée. Plusieurs autres phases, normalement non détectables à partir des spectres $X R D$ ont été trouvées aux joints de grains par $T E M$, telles que le grenat yttrium-aluminium (YAG), (Fe,Zr)Sir $i_{r} \mathrm{SiO}_{\mathrm{r}}$ amorphe et Si élémentaire. La formation de SiC et d'autres phases aux joints de grains est principalement attribuée à l'atmosphère réductrice, la chimie de la matrice et la présence de phase vitreuse avoisinante.

\section{Introduction}

SiAION ceramics are a class of silicon aluminum oxynitrides which have been known and studied 
for decades. ${ }^{1-3}$ Its two major polymorphs, $\alpha^{\prime}$ $\left(\mathrm{M}_{y} \mathrm{Si}_{6-z} \mathrm{Al}_{z} \mathrm{O}_{z} \mathrm{~N}_{8-z} \text { in Gauckler notation }\right)^{4}$ and $\beta^{\prime}$ $\left(\mathrm{Si}_{6-z} \mathrm{Al}_{z} \mathrm{O}_{z} \mathrm{~N}_{8-z}\right)$, have wide ranges of solid solutions and show crystal structures similar to $\alpha$ - or $\beta$ - $\mathrm{Si}_{3} \mathrm{~N}_{4}$, respectively. In addition, the open structure of $\alpha-\mathrm{Si}_{3} \mathrm{~N}_{4}$ can also accommodate additional cations, e.g. $\mathrm{Y}$ or $\mathrm{Mg}$, in interstitial sites. That is also the case for $\alpha^{\prime}$-SiAlON.

A wide variety of SiAlON compositions prepared from $\mathrm{Si}_{3} \mathrm{~N}_{4}, \mathrm{AlN}, \mathrm{Al}_{2} \mathrm{O}_{3}$, and other oxides have been investigated, ${ }^{5.6}$ and are reported in the phase diagrams of many metal- $\mathrm{Al}-\mathrm{Si}-\mathrm{O}-\mathrm{N}$ systems. ${ }^{7.8}$ It is recognized that the phases which appear in these phase diagrams are strongly affected by the starting chemistry of powder and sintering temperature.

As with $\mathrm{Si}_{3} \mathrm{~N}_{4}$, SiAlON powder (either in $\alpha^{\prime}$ - or $\beta^{\prime}$-phase) can be pressurelessly sintered with appropriate oxide additives, such as $\mathrm{Y}_{2} \mathrm{O}_{3}$ or $\mathrm{MgO}$. Near the sintering temperature, the oxide additives react with the native oxide layer on SiAlON powder surface to form aluminosilicate liquids. Liquidphase sintering starts as soon as an eutectic temperature is reached. The eutectic liquid helps the densification and eases the rearrangement of SiAlON particles, and acts as a medium for the process of dissolution-precipitation of oxynitride. . $^{910}$ During the dissolution of the nitride phases or the diffusion of nitrogen from the sintering atmosphere, the liquid phase accommodates nitrogen into the composition. As a result, the liquid phase often has an oxynitride composition in the sintered SiAlON.

Upon cooling, the liquid can form a variety of crystalline or glassy phases, which modify the microstructure and chemistry of grain boundary regions. Similar to the transformation of $\alpha$ - to $\beta$ $\mathrm{Si}_{3} \mathrm{~N}_{4}, \beta^{\prime}$-SiAlON may grow from the liquid phase or $\alpha^{\prime}$-SiAlON grains, as a part of the densification process. This has been classified as a 'solutionprecipitation' process. ${ }^{9,10}$ The formation of YAG in $\mathrm{Y}_{2} \mathrm{O}_{3}$-doped SiAlON systems, and cordierite in the MgO-doped SiAlON system, ${ }^{1}$ during subsequent heat treatment is related to the presence of a liquid phase.

SiAlON exhibits promising mechanical properties at high temperature $\left(>1250^{\circ} \mathrm{C}\right)$, and is a candidate material for turbine component application. Several factors are known to have a major influence on high-temperature performance: ${ }^{12-14}$ the grain morphology of crystalline phases, the chemistry and crystallinity of grain boundaries and porosity can all affect the high-temperature strength and creep resistance.

In this study, the microstructure and chemistry of a sintered carbothermal SiAION were investigated. The formation of $\alpha^{\prime}$-SiAlON from the $\beta^{\prime}$-matrix, the nature and formation of $\mathrm{SiC}$ dispersoids and the recrystallization of the glassy phase were examined, and several types of metallic inclusions were characterized.

\section{Experimental}

\subsection{Powder}

The starting material was an experimental SiAlON powder (produced by Alcoa Technical Center, USA) which was made from a carbothermal reaction and had an average particle size of $0.6 \mu \mathrm{m}$, with $90 \%$ of the powder between 0.1 and $3.0 \mu \mathrm{m}$ (analyzed by Horiba CAPA700 Centrifugal Particle Size Analyzer, Horiba Instruments Inc., USA). The surface area of the powder was about $6 \mathrm{~m}^{2} / \mathrm{g}$ (analyzed by Quantachrome AutoSorb 6.BET unit, Quantachrome Corp., USA). The chemical analysis showed an overall composition $y=0.25$ and $z=0.5$ in the Gauckler notation $\mathrm{Y}_{y} \mathrm{Si}_{6-z} \mathrm{Al}_{z}-$ $\mathrm{O}_{z} \mathrm{~N}_{8-z}$, in which the yttria additive was mixed in the composition before the carbothermic reaction. The amount of cation impurities, mainly $\mathrm{Ca}$ and $\mathrm{Fe}$, is less than $0.5 \mathrm{wt} \%$. The carbon content of the as-received powder is $1.36 \mathrm{wt} \%$ (analyzed by a Carbon Determinator, CS-244 Leco Co., MI, USA). $\beta^{\prime}-$ SiAlON is the only crystalline phase found in the powder by X-ray diffraction (XRD). The powder also contains a small amount of amorphous material which is found mainly in the ultrafine size fraction (less than $0.1 \mu \mathrm{m}$ ) of the powder. The ultrafine fraction is about $3 \mathrm{wt} \%$ and is entirely amorphous by XRD.

\subsection{Material processing}

Green SiAlON pieces were prepared by slip-casting a colloidal slurry on a plaster mold. The dried green sample had a density better than $60 \%$ TD. After being dried at $120^{\circ} \mathrm{C}$, the sample was packed in a graphite crucible and buried in SiAlON powder. Then the whole crucible was sintered in a graphite furnace (Model 1000-4560-FP20, Thermal Tech. Inc., USA) which was ventilated with $1 \mathrm{~atm}$ high purity $\mathrm{N}_{2}$ gas. Nearly dense SiAlON parts ( $99 \%$ TD or over) could be obtained by sintering at temperatures between $1650^{\circ} \mathrm{C}$ and $1720^{\circ} \mathrm{C}$ for $2 \mathrm{~h}$. However, extensive decomposition of SiAlON occurred if the sample was sintered above $1800^{\circ} \mathrm{C}$ and for longer than $2 \mathrm{~h}$.

\subsection{Characterization}

Several important aspects were studied, including the features of $\alpha^{\prime}$ - and $\beta^{\prime}$-SiAlON phases, composition of SiAlON grains, fine inclusions and other grain boundary phases. The powder and sintered 
SiAlON samples were characterized by X-ray diffractometry (Rigaku Giegerflex X-Ray Diffractometer, Japan), carbon determinator, scanning transmission electron microscopy (VG, HB5 STEM, UK), analytical transmission electron microscopy (Hitachi S-530 STEM, Japan) equipped with X-ray energy dispersive spectroscopy (using a windowless detector). XRD analysis was done at room temperature on as-fired or polished surfaces of the sintered specimens. Thin-foil TEM specimens were prepared by ion milling, then coated with a thin carbon layer for electrical conduction. Although quantitative analysis on EDS results was not available (due to the lack of standard SiAlON and other crystalline phases for quantitative calibration of EDS), the light elements, including carbon, nitrogen and oxygen, were qualitatively determined. For microanalysis, the diameter of the electron beam was converged to less than $1 / 3$ of the size of the analyzed feature. Other possible artefacts, such as thickness effects or carbon signal from the coated carbon layer, were tested and prevented.

\section{Results}

After sintering at $1700^{\circ} \mathrm{C}$ for $2 \mathrm{~h}$, the dense sample has a complex microstructure. Figure 1 is a TEM micrograph of a typical SiAlON of this kind. The $\beta$ '-SiAlON grains are equiaxed and several microns in size, and contain many fine inclusions and line defects which will be revealed in the later micrographs. Only a few, $\beta^{\prime}$-SiAlON grains have faceted surfaces. The glassy boundary layers, shown as the dark features in Fig. 1, are located either between SiAlON grains or segregated at triple points. In some big glassy regions, submicron crystalline grains were imaged with diffraction contrast. These submicron grains have yttrium and calcium in the composition different from that of the surrounding $\boldsymbol{\beta}^{\prime}$-SiAlON grains.

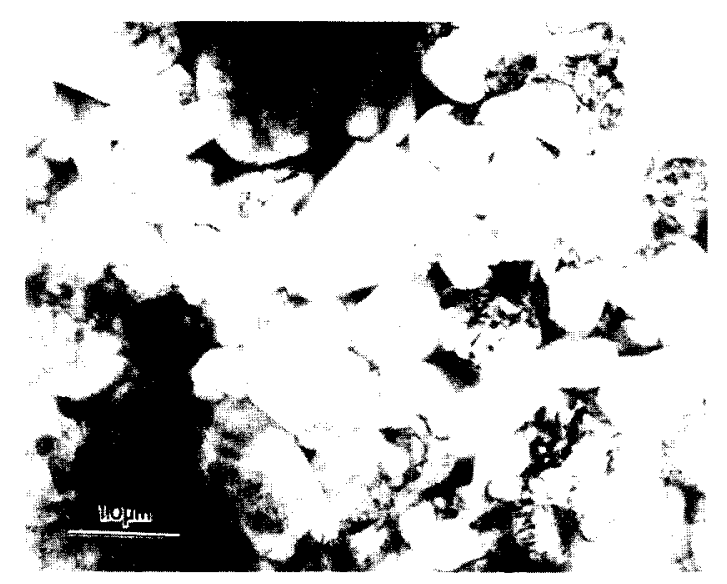

Fig. 1. Sintered SiAION specimen imaged TEM bright field condition.

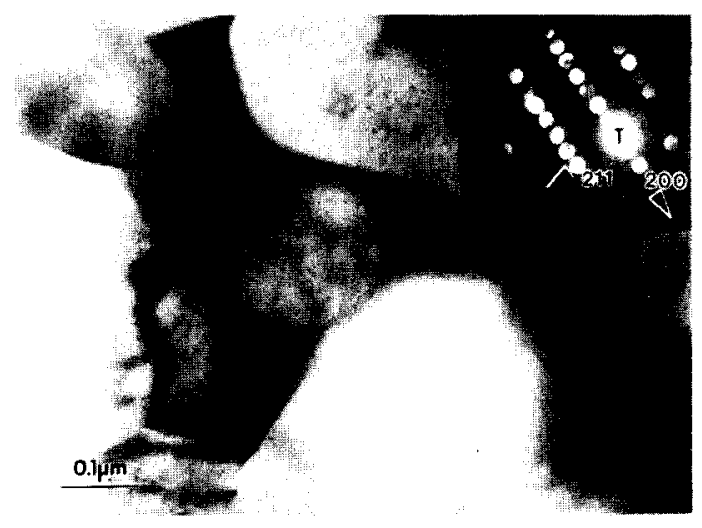

Fig. 2. Submicron grain boundary phase (arrow) and its electron diffraction pattern, which is indexed as an $\alpha^{\prime}-$ SiAlON.

\section{$3.1 \beta^{\prime}$ - and $\alpha^{\prime}$-SiAlON grains}

Figure 2 is a TEM bright field micrograph of a $\alpha^{\prime}$-SiAlON grain and its electron microdiffraction pattern. The $\alpha^{\prime}$-grains were smaller than the matrix $\beta^{\prime}$-grains, and were only observed inside glassy regions. Two possible polymorphs, $\alpha^{\prime}$ and $\beta^{\prime}$, of SiAlON materials were studied and $\mathrm{Jack}^{7}$ reported that their structure and chemistry are distinctively different. Figure 3 contains two EDS spectra showing the chemical composition of either $\beta^{\prime}$-SiAION or $\alpha^{\prime}$-SiAION (of the pointed grain in Fig. 2), respectively. The $\beta$-phase has mostly $\mathrm{Si}$ and $\mathrm{N}$, and contains small amounts of $\mathrm{Al}$ and $\mathrm{O}$. The intensity ratio of $\mathrm{Si} / \mathrm{Al}$ is about 10 . The $\alpha^{\prime}$-phase has a similar $\mathrm{Si} / \mathrm{Al}$ ratio as a $\beta^{\prime}$ -
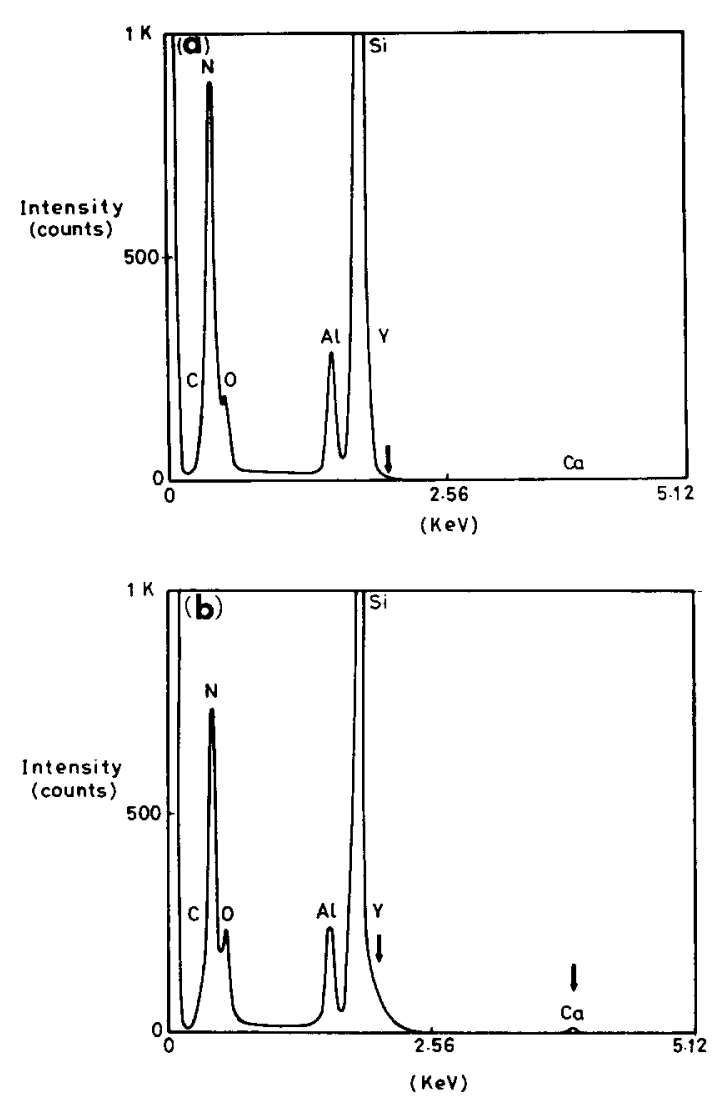

Fig. 3. EDS spectra obtained from (a) $\beta^{\prime}-$ SiAION grain and (b) $\alpha^{\prime}$-SiAlON grain which is shown in Fig. 2. 
grain, except its composition has additional $\mathrm{Y}$ and $\mathrm{Ca}$.

Another form of $\alpha^{\prime}$-SiAlON was found as whiskers on the surfaces of degraded SiAlON specimens processed in reducing atmosphere, as shown in the SEM micrographs in Fig. 4(a). Severely degraded surfaces have enough $\alpha^{\prime}$-phase whiskers to be detectable by XRD. These whiskers were also found occasionally on the surface of the internal surface. The identity of these interior whiskers as $\alpha^{\prime}$-phase was confirmed by TEM and EDS. Figure 4(b) is the TEM bright field micrograph of an a $\alpha^{\prime}-\mathrm{SiAlON}$ whisker, which is similar to the whisker features illustrated by SEM in Fig. 4(a). The whisker in Fig. 4(b) consists of an $\alpha^{\prime}-$ crystal with a similar composition as the $\alpha^{\prime}$-grains in Fig. 2(b). The whisker appears to be surrounded by glassy material.

\subsection{Fine inclusions in $\beta^{\prime}-\mathrm{SiAlON}$ grains}

An appreciable amount of fine inclusions with sizes from 10 to $50 \mathrm{~nm}$ were observed within large $\beta^{\prime}$-SiAlON grains. As shown in Fig. 5 these inclusions are circular features with a characteristic internal laminar structure. Figure $5(\mathrm{~b})$ is the cen-
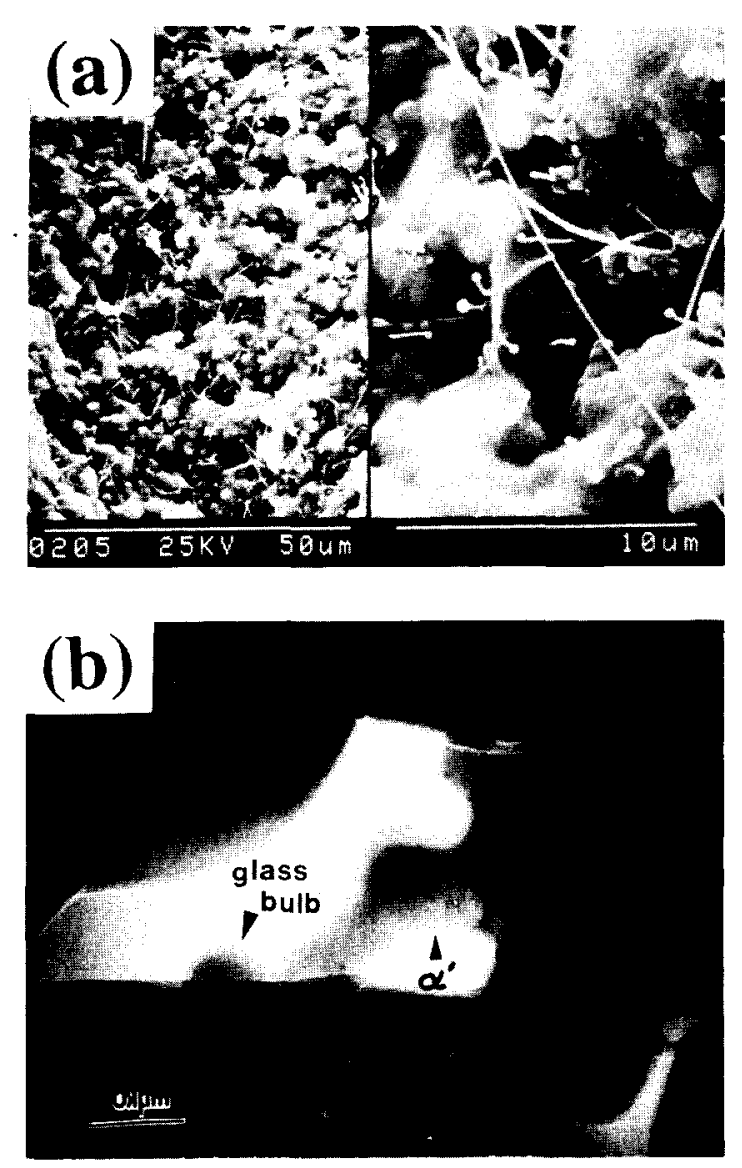

Fig. 4. (a) SEM micrographs illustrate the surface morphologies of an as-fired surface of a SiAlON specimen; (b) TEM micrograph shows that a whisker originates on the surface of an internal surface. The $\alpha^{\prime}$-SiAlON grain at the base of the whisker was proven to have a similar composition to that shown in Fig. 3(b). tered dark field (CDF) micrograph of the region in Fig. 5(a). Only part of the inclusions are illuminated in this dark field image with part of the discontinuous diffraction ring. The inserted electron diffraction pattern (DP) in Fig. 5(b) shows several diffraction intensities from the inclusions, indicating that these inclusions are randomly oriented. Figure 6 illustrates one of these inclusions near the edge of the thin-foil SiAlON specimen. Therefore, the thickness of the inclusion is through foil and a reliable chemical analysis of the inclusion can be obtained. This inclusion was analyzed by a converged electron beam in a diameter $1.5 \mathrm{~nm}$, and the analyzed region was contaminated by a carbon (black) spot, as shown in Fig. 6. The Xray energy dispersive spectrum was collected by a windowless EDS detector and could reveal light elements, such as carbon and oxygen. The EDS spectrum of this inclusion shows only $\mathrm{Si}, \mathrm{C}$ and a minor amount of oxygen. The oxygen intensity should come from the native surface oxide layer which is formed while a non-oxide $\mathrm{Si}_{3} \mathrm{~N}_{4}$ or SiAlON is exposed to atmosphere. The EDS result suggests that the inclusion is silicon carbide.
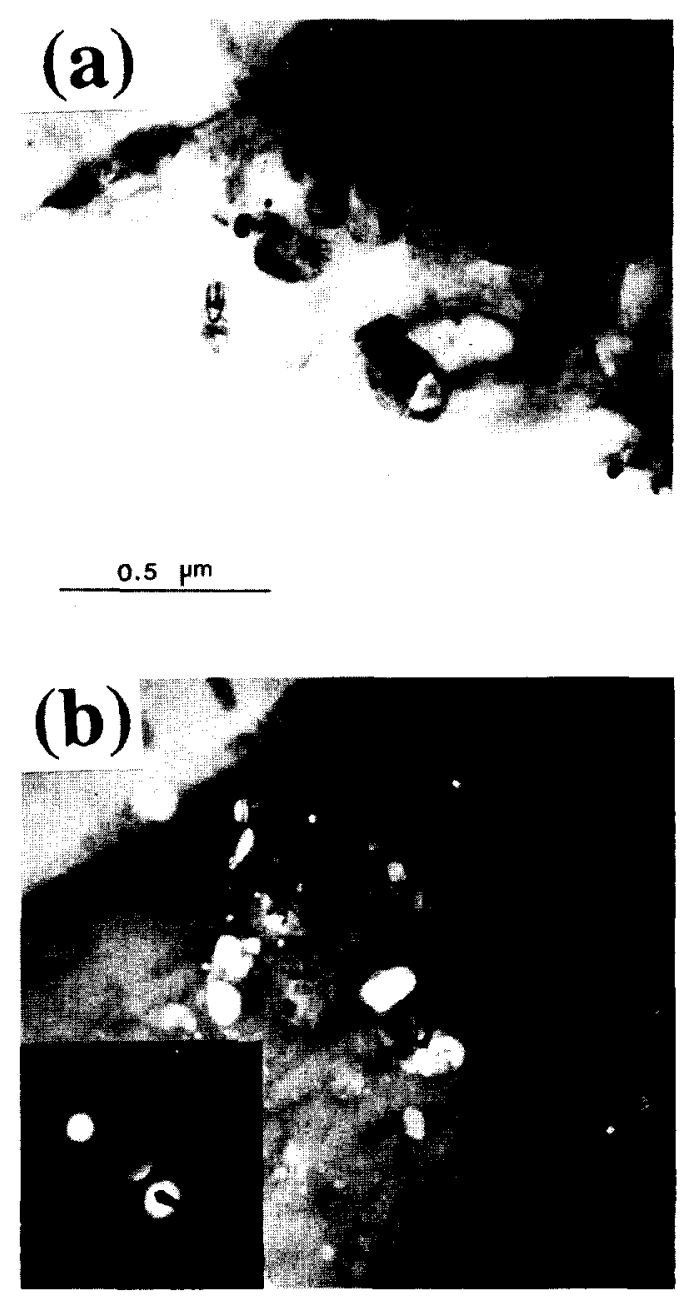

Fig. 5. Circular inclusions in a $\beta^{\prime}-$ SiAlON grain: (a) bright field and (b) centered dark field TEM micrographs and inserted electron diffraction pattern of the imaging region. 


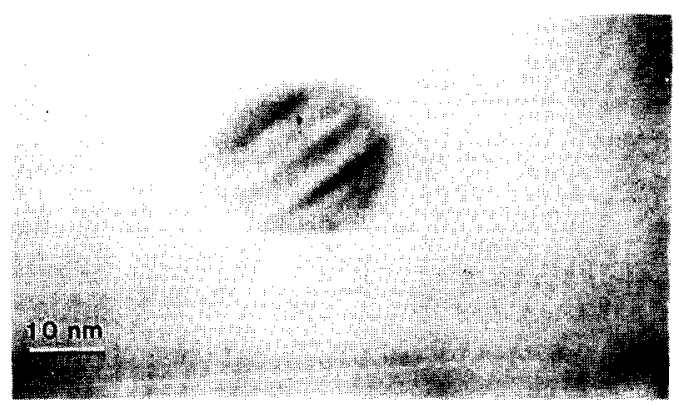

(a)

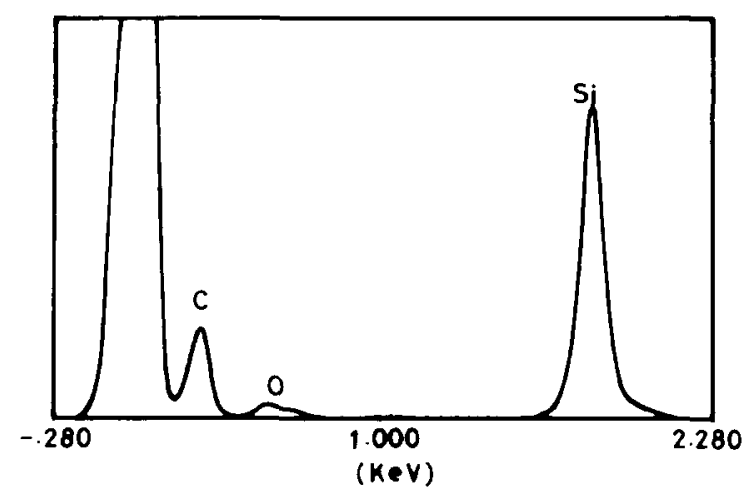

(b)

Fig. 6. (a) STEM micrograph and (b) EDS spectrum of an inclusion which is found in a $\beta^{\prime}$-SiAION grain. A black dot on the inclusion is the carbon contamination formed by the convergent electron beam during analysis.

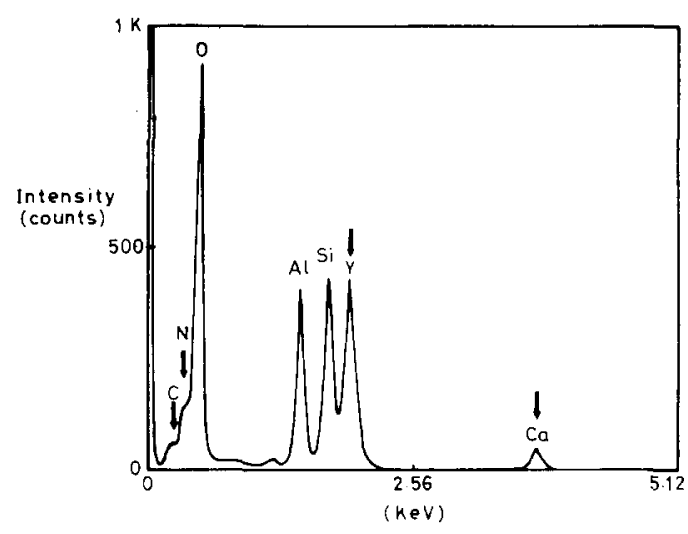

(a)

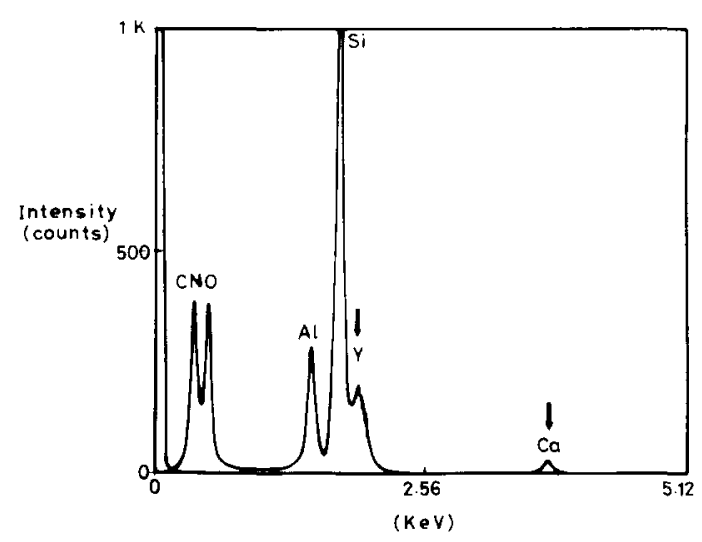

(b)

Fig. 7. EDS spectra of two different glassy phases: (a) a typical glassy pocket; (b) a glassy pocket next to a recrystallized YAG grain.

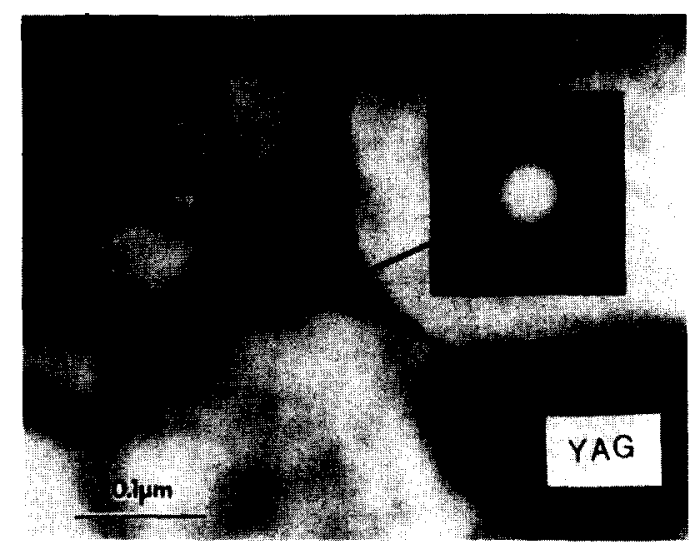

Fig. 8. STEM micrograph of a glassy pocket, with a composition of $\mathrm{SiO}_{x}$, surrounded by one YAG and three $\beta$-SiAION grains.

\subsection{Composition of glassy boundaries}

Three types of glassy phases were identified at SiAlON grain boundaries. Most of the glasses at grain boundaries have a yttrium-aluminum-silicon oxynitride composition. Figure $7(\mathrm{a})$ is an EDS spectrum that illustrates the composition of a glassy phase adjacent to $\beta$ '-SiAlON grain, showing that a substantial amount of $\mathrm{Al}$ and $\mathrm{Y}$ is retained in the glass at this location. In comparison, the glassy region next to a YAG precipitate (Fig. 7(b)) has a different concentration of $\mathrm{Al}, \mathrm{Si}$ and $\mathrm{Y}$. It is noted that both glassy regions contain traces of $\mathrm{Ca}$ element. In other regions of the same sample (Fig. 8), a nearly pure $\mathrm{SiO}_{x}$ phase was identified by EDS. It is located at a triple point between three crystalline grains, $\alpha^{\prime}-, \beta^{\prime}-\mathrm{SiAlON}$ and YAG. As the inserted electron DP shows in Fig. 8, the $\mathrm{SiO}_{\mathrm{x}}$ is amorphous.

\subsection{Crystalline phases at grain boundaries}

Silicon is often reported as a free element in $\mathrm{Si}_{3} \mathrm{~N}_{4}$ powder, and may persist in the SiAlON at high temperature. ${ }^{16.17}$ Figure 9 is a bright field image of a $100 \mathrm{~nm}$ silicon particle surrounded by a glassy phase in the SiAION matrix. EDS shows that this particle was nearly pure elemental silicon. The size
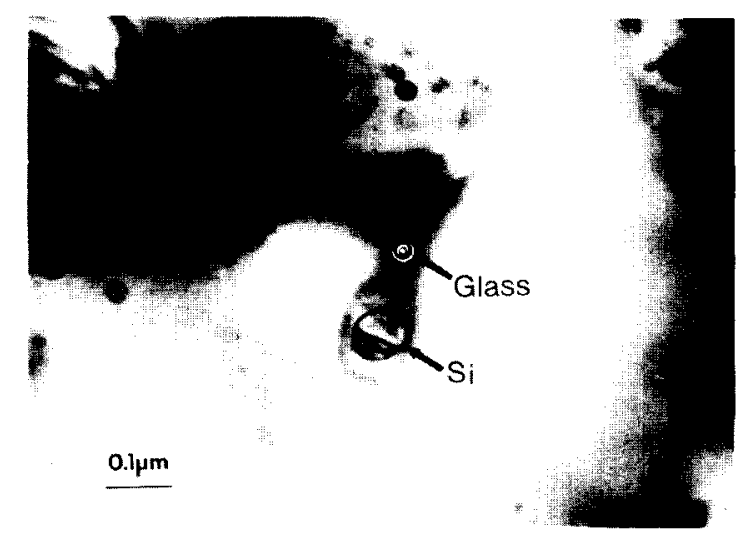

Fig. 9. TEM micrograph illustrates a metallic silicon included in $\beta$-SiAlON matrix, but engulfed in a glassy phase. 


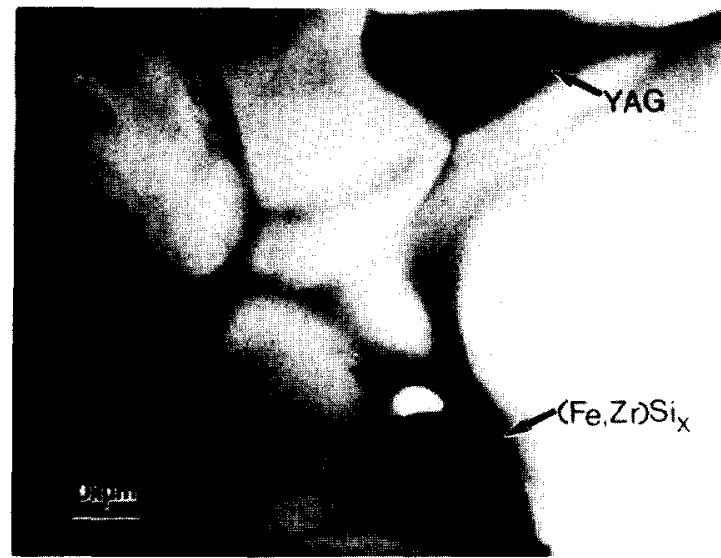

Fig. 10. STEM micrograph showing a $(\mathrm{Fe}, \mathrm{Zr}) \mathrm{Si}_{x}$ grain neighboring the SiAION matrix.

of $\mathrm{Si}$ inclusions can increase to $1 \mu \mathrm{m}$ if the sintering of SiAlON is conducted at temperature higher than $1800^{\circ} \mathrm{C}$.

Cation impurities, including $\mathrm{Ca}$ and $\mathrm{Fe}$, were reported by the powder supplier at a level less than $0.5 \mathrm{wt} \%$. The calcium is mostly found in the glassy boundaries, but may partially precipitate with yttrium and other elements to form $\alpha^{\prime}$ SiAlON, as the $\alpha^{\prime}$-grains shown in Figs 2 and 4 . The iron impurity is only found as a silicide compound, $\mathrm{FeSi}_{x}$. Occasionally, this silicide phase is revealed on the fracture surface of SiAION material as a fracture origin.

Another impurity, $\mathrm{Zr}$, is from the contamination by $\mathrm{ZrO}_{2}$ grinding media. The zirconia (less than $0.1 \mathrm{wt} \%$ ) was reduced in the carbon-rich sintering atmosphere. No pure zirconia phase was found in the sintered matrix by XRD and TEM. Some reduced zirconia reacted with yttrium and formed an iron zirconium silicide $(\mathrm{Fe}, \mathrm{Zr}) \mathrm{Si}_{x}$ compound, such as the grain pointed out in Fig. 10.

These features, including $\alpha^{\prime}-\mathrm{SiAlON}, \mathrm{SiC}, \mathrm{SiO}_{x}$, silicides and glassy grain boundary phases, are in small amounts that are not detectable by XRD in this work. These inclusions and grain boundary phases are thought to be the regular structural elements in this specific SiAlON material rather than artifacts present in occasional samples.

\section{Discussion}

The SiAION powder was made by a carbothermal reduction process in which oxides and carbon powders were reacted in a nitrogen-rich atmosphere at temperatures up to $1650^{\circ} \mathrm{C}$. The overall composition of this SiAlON was confined in the compatible ternary region of $\beta^{\prime}$-SiAlON, $\alpha^{\prime}$ SiAlON, and YAG. ${ }^{19}$ The powder was not a pure $\beta$ '-SiAION solid solution, but rather a mixture of $\beta^{\prime}-\mathrm{SiAlON}$, glassy phase, and some minor ingredi- ents, including $1.36 \mathrm{wt} \%$ carbon and/or carbide. Because the processing temperature of the powder was only $1650^{\circ} \mathrm{C}$, chemical uniformity was not fully achieved after the nitridation step, so individual SiAION particles might have a composition different from the average. In addition, the powder contained the carbon and iron oxide residue which was used as a nitridation catalyst for making SiAlON powder.

\subsection{Formation of $\alpha^{\prime}$-SiAlON}

Although the samples have only $\beta^{\prime}$-phase on XRD patterns before and after $1700^{\circ} \mathrm{C}$ sintering, an appreciable amount of $\alpha^{\prime}$-phase is detected by AEM at glassy boundaries and on some high-temperature $\left(\geq 1800^{\circ} \mathrm{C}\right)$ sintered and degraded surfaces. The amorphous phase and $\beta^{\prime}$-phase in as-received powder are not at the equilibrium composition for $1700^{\circ} \mathrm{C}$. During sintering at $1700^{\circ} \mathrm{C}$, the liquid phase dissolves more nitride and its composition moves toward $\mathrm{Si}_{3} \mathrm{~N}_{4}$-rich composition, approaching the composition near the liquidus line in the $\mathrm{Si}-\mathrm{Al}-\mathrm{Y}-\mathrm{O}-\mathrm{N}$ phase diagram. The new $\alpha^{\prime}$-grains grow either by dissolving $\beta^{\prime}$-phase in this liquid phase as the temperature is raised to the sintering temperature, or the grains more possibly precipitate from an over-saturated liquid phase during furnace cooling.

The growth of $\alpha^{\prime}$-SiAlON whiskers on the assintered surface is related to an increase of $\mathrm{Al}$ and $\mathrm{N}$ content on the decomposed SiAlON surface. ${ }^{13}$ The skin of over-sintered SiAION becomes rich in aluminum content as a $\mathrm{SiO}$ vapor or elemental $\mathrm{Si}$ vapor is volatilized from SiAlON surface. The formation of the volatile species would be enhanced in carbonaceous atmospheric conditions in the graphite furnace. The composition, after loss of $\mathrm{SiO}$, becomes oversaturated in yttrium, calcium and aluminum. As a consequence, the residual elements are crystallized to form $\alpha^{\prime}$-SiAlON through the grain boundary liquid. The evidence also reveals that a vapor-enhanced liquid-solid (LS) process results in the formation of $\alpha^{\prime}$-whiskers. Figure 4(b) clearly shows a glassy bulb, being a liquid at high temperature, located at the top of the whisker. The presence of the liquid phase is essential for the growth of $\alpha^{\prime}-\mathrm{SiAlON}$, as it may allow the dissolution of $\beta^{\prime}$-grains and the growth of $\alpha^{\prime}$-grains.

\subsection{Compositional changes of glassy phases}

The local composition of the glassy phase is determined by the equilibrium condition at the sintering temperature, and by liquid-crystal reactions during cooling. The composition of the glass adjacent to the $\beta^{\prime}$-grains, shown in Fig. $7(\mathrm{a})$, is in equilibrium with $\beta^{\prime}$ - and $\alpha^{\prime}$-SiAlONs at $1700^{\circ} \mathrm{C}$. 
However, the equilibrium composition of the liquid-phase changes during cooling, and becomes over-saturated in $\mathrm{Y}, \mathrm{Al}$ and $\mathrm{N}$. The resulted YAG or additional $\alpha^{\prime}$-SiAION grains from the cooling liquid changes its composition locally. For example, the glass adjacent to YAG precipitates is depleted in yttrium and aluminum (Fig. 7(b)). Further precipitation of $\alpha^{\prime}$-SiAlON depletes more $\mathrm{Y}$ and $\mathrm{Al}$ from the glass, leaving nearly pure silica (Fig. 8). The overall composition changes should be consistent with the composition evolution of a liquid in the $\mathrm{YAG}-\mathrm{SiO}_{2}-\left(\alpha^{\prime}-\mathrm{SiAlON}\right)$ phase region.

Recrystallization of a glassy phase is considered to be a local phenomenon affecting the composition of glassy regions. That has been previously reported by Bonnell et al. ${ }^{11}$ who determined compositional variations within the SiAlON grains arising from a solution precipitation mechanism. They concluded that the $\mathrm{Al}$ concentration within the grains could vary as additional SiAlON grows onto existing grains at low temperature. The observations presented here complement Bonnell et al. by documenting the corresponding compositional changes in the neighboring glassy phase.

\subsection{Formation of $\mathrm{SiC}$ inclusions and metallic phases}

The residual carbon $(1.36 \mathrm{wt} \%)$ in the as-received SiAlON powder and sintering in carbonaceous atmosphere might contribute to the formation of $\mathrm{SiC}$ and metallic phases. At conditions near the decomposition temperature $\left(1800^{\circ} \mathrm{C}\right)$ of $\mathrm{Si}_{3} \mathrm{~N}_{4}$, the $\mathrm{Si}$ (either in vapor or in liquid states) is generated at equilibrium with $\mathrm{Si}_{3} \mathrm{~N}_{4}$, via the reactions:

$$
\begin{aligned}
\mathrm{Si}_{3} \mathrm{~N}_{4} & \rightarrow 3 \mathrm{Si} \text { (liquid) }+2 \mathrm{~N}_{2} \text { (gas) } \\
\mathrm{Si} \text { (liquid) } & \rightarrow \mathrm{Si} \text { (vapor) }
\end{aligned}
$$

It is likely that this reaction occurs in the SiAlON as well, which could account for the observation of a metallic silicon inclusion as shown in Fig. 9.

As discussed previously, YAG is formed as an equilibrium phase by precipitation from a $\mathrm{Y}$ - and Al-rich liquid at a low processing temperature. In contrast, metallic silicon, $(\mathrm{Fe}, \mathrm{Zr}) \mathrm{Si}_{x}$ and $\mathrm{SiC}$ are formed as a consequence of the reaction of SiAlON in the carbonaceous reducing environment of the graphite sintering furnace. Iron silicide is made up from iron introduced as $\mathrm{Fe}_{2} \mathrm{O}_{3}$ used as a nitridation catalyst during powder manufacturing, while the $\mathrm{ZrO}_{2}$ is an impurity from grinding media. These are reduced to form silicide phases, such as $(\mathrm{Fe}, \mathrm{Zr}) \mathrm{Si}_{x}$. However, zirconium nitride $(\mathrm{ZrN})$ or oxynitride, which may appear in zirconiadoped silicon nitride composites, was not detected in the SiAlON.

The formation of $\mathrm{SiC}$ phase in carbon-rich HIPed $\mathrm{Si}_{3} \mathrm{~N}_{4}$ has been investigated by others. ${ }^{20,21}$
The reaction of residual carbon with $\mathrm{SiO}_{2}$ to form $\mathrm{SiC}$ and $\mathrm{CO}$ gas during sintering is proposed, and is more favorable at high temperature $\left(1700^{\circ} \mathrm{C}\right)$. Their evidence provides the possibility of $\mathrm{SiC}$ formed in SiAION powder. A similar feature of inclusions in $\beta-\mathrm{Si}_{3} \mathrm{~N}_{4}$ was reported ${ }^{22}$ in that parallel fringes in the inclusions in Figs 5 and 6 are similar to those in Ref. 22. These fringes are suggestive of stacking faults commonly found in polycrystalline silicon carbide. The fringes shown in these inclusions can be the same planar defect; perhaps the stacking faults are formed to accommodate the lattice mismatch in SiAlON matrix.

\section{Conclusions}

A submicron carbothermally produced $\beta^{\prime}$-SiAlON powder was pressureless sintered above $1650^{\circ} \mathrm{C}$ by liquid-phase sintering. The major microstructural features of the densified SiAlON were equiaxed $\beta$-grains, several microns in size, bonded with small amount of glassy phases. Several secondary phases and inclusions were found by means of TEM inside the $\beta^{\prime}$-grains and at the glassy boundaries.

A small amount of $\alpha^{\prime}$-SiAlON is possibly formed during sintering or cooling. ${ }^{23}$ The $\alpha^{\prime}$-grains often grow in the glassy pockets, as circular inclusions in sizes less than $0.5 \mu \mathrm{m}$. Some of the yttrium dopant and calcium impurity, initially present in the glassy phase, is compounded in the $\alpha^{\prime}$-SiAlON. Other types of $\alpha^{\prime}$-SiAlON can also be observed in the form of whiskers decorating the surfaces of over-sintered specimens. The $\alpha^{\prime}$-whiskers grow by a vapor-enhanced liquid-solid process in the presence of a $(\mathrm{Y}, \mathrm{Ca})$-containing liquid. The formation of $\alpha^{\prime}$-SiAlON is controlled by the chemical conditions of neighboring $\alpha^{\prime}-, \beta^{\prime}-\mathrm{SiAION}$ and glassy phase.

Several other phases, including yttrium-aluminum garnet (YAG), $(\mathrm{Fe}, \mathrm{Zr}) \mathrm{Si}_{x}$, amorphous $\mathrm{SiO}_{x}$ and elemental $\mathrm{Si}$ were found at grain boundaries, but not enough to be detected by XRD in this study. The YAG phase formed during cooling by precipitation from $\mathrm{Y}-\mathrm{Al}-\mathrm{Si}-\mathrm{ON}$ glass boundaries. The local composition of the glass phase was found to vary, depending upon the degree of crystallization of YAG and $\alpha^{\prime}$-SiAlON. This also produced nearly pure silica glass in the sintered SiAlON material. Some of the fine $\mathrm{SiC}$ inclusions, $10-50 \mathrm{~nm}$ in diameter, were formed mostly in $\beta^{\prime}$-SiAlON grains due to carbonaceous reducing conditions, which also brought about $\mathrm{Si}$ inclusions. Iron silicides and iron-zirconium silicides were observed to be the reaction products of reduced $\mathrm{Si}$ with impurity oxides. 


\section{Acknowledgement}

The authors greatly appreciate help from Professor Tony Garret-Reed at MIT for analyzing the composition of some interesting structural features. The research work was partially done in Ceramics Process Systems Co., Massachusetts, USA.

\section{References}

1. Jack, K. H., The characterization of $\alpha^{\prime}$-sialon and the $\alpha-\beta$ relationships in sialon and silicon nitrides. In Progress in Nitrogen Ceramics, ed. F. L. Riley. Martinus Nijhoff Publisher, Boston/The Hague/Dordrecht/Lancaster, 1983, pp. 45-59.

2. Jack, K. H., Sialons: a study in materials development In Non-oxide Technical and Engineering Ceramics, ed. S. Hampshire. Elsevier Applied Science, London and New York, 1986, pp. 1-30.

3. Thompson, D. P., Korgul, P. \& Hendry, A., The structural characterization of sialon polytypoids. In Progress in Nitrogen Ceramics, ed. F. L. Riley. Martinus Nijhoff Publisher, Boston/The Hague/Dordrecht/Lancaster, 1983, pp. $61-74$.

4. Nail, I. K., Gauckler, L. J. \& Tien, T. Y., Solid-liquid equilibria in the system $\mathrm{Si}_{3} \mathrm{~N}_{4}-\mathrm{AlN}-\mathrm{SiO}_{2}-\mathrm{Al}_{2} \mathrm{O}_{3} . J . A m$ Ceram. Soc., 61(7-8) (1978) 332-5.

5. Ishizawa, K., Ayuzawa, N., Shiranita, A., Takai, M. Uchida, N. \& Mitomo, M., Some properties of $\alpha^{\prime}$-sialon ceramics. In Ceramic Materials and Components for Engines, Proceedings of the Second International Symposium, ed. W. Bunk \& H. Hausner. Verlag Deutsche Keramische Gesellschaft, 1986, pp. 511-18.

6. Hampshire, S., O'Reilly, K. P. J., Leigh, M. \& Redington, M., Formation of $\alpha^{\prime}$-sialon with neodymium and samarium modifying cations. Presented at World Congress on High Tech Ceramics, Milan, June 1986.

7. Jack, K. H., Review-sialon and related nitrogen ceramics J. Mat. Sci., 11 (1976) 1135-58.

8. Slasor, S. \& Thompson, D. P., Preparation and characterization of yttrium $\alpha$-sialon. In Non-oxide Technical and Engineering Ceramics, ed. S. Hampshire, Elsevier Applied Science, London and New York, 1986, pp. 223-30.

9. Lumby, R. J., North, B. \& Taylor, A. J., The formulation of single phase sialon ceramics. In Progress in
Nitrogen Ceramics, ed. F. L. Riley, Martinus Nijhoff Publisher, Boston/The Hague/Dordrecht/Lancaster, 1983 pp. 393-404.

10. Hampshire, S., The rule of additives in the pressureles sintering of nitrogen ceramics for engine application. Metal Forum, 7(3) (1984) 162-70.

11. Bonnell, D. A., Ruhle, M. \& Tien, T.-Y., Redistribution of aluminum ions during processing of sialon ceramics. J. Am. Ceram. Soc., 69(8) (1986) 623-7.

12. Lumby, R. J., Butler, E. \& Lewis, M. H., Lucas syalons: composition, properties and uses. In Progress in Nitrogen Ceramics, ed. F. L. Riley. Martinus Nijhoff Publisher, Boston/The Hague/Dordrecht/Lancaster, 1983, pp. 68394

13. Ekstrom, T. \& Ingelstrom, N., Characterization and properties of sialon materials. In Non-oxide Technical and Engineering Ceramics, ed. S. Hampshire, Elsevier Applied Science, London and New York, 1986, pp. 231-54.

14. Ingelstrom, N. \& Ekstrom, T., Relation between composition, microstructure and cutting tool performance of $\alpha$-, $\beta$-SiAlON. J. Phys. (1986) C1-347.

15. Wotting, G. \& Ziegler, G., Powder characteristics and sintering behaviour of $\mathrm{Si}_{3} \mathrm{~N}_{4}$-powder. Part I: Powder characterization. Interceram., 2 (1986) 32-5.

16. Greskovich, C. \& Prochazka, S., Stability of silicon nitride and liquid phase(s) during sintering. Comm. Am. Ceram. Soc., 64 (1981) C-97-97.

17. Hirosaki, N. \& Okada, A., Effect of nitrogen gas pressure on sintering of $\alpha$ - and $\beta$-SiAlON. J. Ceram. Soc. Jpn. Inter. Edn., 95 (1987) 200-4.

18. Phelps, F. E., Bogel, P. J. \& Troup, R. L., Process for producing $\beta^{\prime}$-silicon aluminum oxynitride ( $\beta^{\prime}$-SiAlON). US Patent 4511666, 16 April 1985.

19. Slasor, S. \& Thompson, D. P., Comments on 'TwoDimensional Solid Solution Formation of Y-containing $\alpha-\mathrm{Si}_{3} \mathrm{~N}_{4}$. J. Mat. Sci. Lett., 6 (1987) 315-16.

20. Watari, K., Ishizaki, K. \& Kawamoto, M., Evaluation of carbon behavior in HIPed silicon nitride. J. Ceram. Soc. Jpn. Inter. Edn., 96 (1988) 741-8.

21. Watari, K. \& Ishizaki, K., Influence of gas pressure on HIP sintered silicon nitride and stability of carbon impurity. J. Ceram. Soc. Jpn. Inter. Edn., 96 (1988) 53540.

22. Falk, L. K. L. \& Dunlop, G. L., The microstructure of $\mathrm{Si}_{3} \mathrm{~N}_{4}$ formed by nitridation and pressure sintering of Si-Si ${ }_{3} \mathrm{~N}_{4}$ compacts. Mater. Sci. Eng., 71 (1985) 123-30.

23. Mandal, H., Thompson, D. P. \& Ekstrom, T., Reversible $\alpha \Leftrightarrow \beta$ sialon transformation in heat-treated sialon ceramics. J. Eur. Ceram. Soc., 12 (1993) 421-9. 